\title{
Methadone Prescription Patterns among Pain Physicians in Colombia
}

\section{Patrones de prescripción de metadona entre médicos colombianos especialistas en manejo del dolor}

Date received: 26/07/2017 | Date accepted: 27/10/2017

\author{
Diego Alberto Moreno Martínez \\ Pontificia Universidad Javeriana, Colombia \\ Paola Nathaly Silva Enríquez ${ }^{b}$ \\ Universidad de La Sabana, Colombia \\ Jairo Ricardo Moyano Acevedo ${ }^{c}$ \\ Hospital Universitario Fundación Santa Fe de Bogotá,
}

Colombia

a Physician, Department of Anesthesiology and Pain Medicine, Faculty of Medicine, Pontificia Universidad Javeriana-Hospital Universitario San Ignacio, Bogotá, Colombia.

b Anesthesiology and Perioperative Medicine Resident, Universidad de La Sabana, Chía, Colombia. Medical surgeon, Pontificia Universidad Javeriana, Bogotá, Colombia.

c Physician, Department of Anesthesiology and Pain Medicine, Hospital Universitario Fundación Santa Fe de Bogotá, Bogotá, Colombia.

How to cite: Moreno Martínez DA, Silva Enríquez PN, Moyano Acevedo JR. Methadone Prescription Patterns among Pain Physicians in Colombia. Univ. Med. 2018;59(3). doi: https://doi.org/10.1114 4/Javeriana.umed59-3.ppmm

\begin{abstract}
Background: Chronic pain is a disease with serious consequences for people, physicians, and health care systems. Chronic opioid usage is one of the therapy strategies. Methadone is among the available opioids in Colombia and it is characterized by unique pharmacological properties and increased mortality reports because of overdose and cardiovascular complications. Appropriate monitoring and prescribing patterns of methadone are associated with complications similar to chronic management with other opioids. Aim: To describe methadone prescribing patterns among Colombian pain physicians and compare them to the accepted recommendations by the international scientific community. Materials and Methods: An electronic structured survey was applied to pain specialist physicians identified through major pain study associations and national training programs. Results: Respondents of the survey are mostly experienced university certified physicians and anesthesiologists with clinical training working at university hospitals. Most of them perceive chronic opioid therapy as an effective strategy for pain relief and functional outcomes despite the lack of empirical support. Most of them know clinical practice guidelines but are not applying them despite this matter. Conclusions: We must enhance education for prescribers in order to improve patient safety. The recommended clinical practice guidelines are poorly applied by Colombian doctors. The results of this study must be cautiously assessed.
\end{abstract}

Keywords

methadone; prescription drugs; opioid analgesics; chronic pain.

\section{RESUMEN}

Introducción: el dolor crónico es una enfermedad con graves consecuencias para personas, médicos y sistemas de salud. Una de las estrategias de manejo es el uso prolongado de opioides, y dentro de los disponibles en Colombia se encuentra la metadona, con características farmacológicas únicas y asociación con aumento de mortalidad por sobredosis y complicaciones cardiovasculares. La adecuada prescripción y seguimiento de metadona se relaciona con complicaciones similares al manejo con otros opioides. Objetivo: describir 
los patrones de prescripción de metadona entre médicos colombianos especialistas en manejo de dolor y comparar estos patrones de prescripción con las recomendaciones mayormente aceptadas por la comunidad científica internacional. Materiales y métodos: se utilizó una encuesta electrónica estructurada aplicada entre médicos especialistas en dolor identificados a través de las principales agremiaciones y programas de formación nacionales. Resultados: los encuestados que respondieron son mayoritariamente experimentados, anestesiólogos, con entrenamiento universitario clínico y que trabajan en hospitales universitarios. La mayoría de ellos percibe como efectivo el manejo a largo plazo con opioides para el control analgésico y la mejoría funcional, a pesar de la falta de respaldo empírico. La mayoría no aplica las herramientas recomendadas por guías de práctica clínica, aunque las conocen. Conclusiones: se debe mejorar la educación de prescriptores de metadona para mejorar la seguridad de los pacientes. Se infiere pobre aplicabilidad de herramientas recomendadas por guías de práctica clínica en el medio colombiano. Los resultados de la presente encuesta no son fácilmente generalizables.

Palabras clave

metadona; medicamentos de prescripción; analgésicos opioides; dolor crónico.

\section{Introduction}

Chronic pain induces changes in the central nervous system that explain different biological, psychological, social and/or functional complications, with consequences for the individual, health systems and societies $(1,2)$. Throughout the history of opioids as analgesics, there has been a transition from the underuse of these to the promotion by pharmaceutical industries, the marketing of new presentations, the sponsorship of organizations for pain management, up to the use of clinical practice guidelines (3). This partly explains the disproportionate and unequal increase in the consumption of opioids in different developed countries in the last two decades.

One of the multiple causes of inappropriate prescription of opioids is the inadequate training and updating of the persons in charge $(4,5)$. In Colombia there are paradoxical circumstances; for example, the inadequate availability of opioids (associated with the problem of pain control) in clinical circumstances where these have proven to be effective and safe; as well as the indiscriminate prescription of these in clinical contexts, where their effectiveness and safety are highly questioned $(5,6)$.

Methadone, a synthetic opioid used for the treatment of opioid addiction $(7,8)$ and chronic pain $(9,10)$, has unique pharmacological and clinical characteristics among the group of opioids available in Colombia. Its advantages include: 1) antagonism of $\mathrm{N}$-methyl-D-aspartate receptors; 2) when an adequate plasmatic concentration is reached, it can be used at longer intervals, which is convenient for patients, and 3) lower cost compared to other long-acting opioids.

Its disadvantages include:

1. Variable half-life: in most cases it is between 14 and 60 hours; however, cases of half-life of up to 120 hours have been reported $(7,11)$, compared to the average half-life of most available opioids (morphine, hydromorphone, oxycodone, fentanyl), which varies between 2 and 3.5 hours. Taking as a reference the longest half-life, that is, 60 hours, the steady-state concentration is only reached after 12 days (5 half-lives) and, in some cases, even after three weeks $(12,13)$. This exposes patients to toxic doses if a monitored titering process is not carried out.

2. The equianalgesic doses for conversion to other opioids (milliequivalents of morphine) are very variable. For low doses of morphine it is proposed between 3:1 and 10:1, and for high doses, between 8:1 and 20:1 (14). This, added to the incomplete cross-tolerance between opioids, makes shifting from any opioid to methadone or vice versa a challenge and requires careful management to avoid adverse effects.

3. The potential for drug interactions is important: drugs that interfere with pharmacokinetics (mainly inducers or inhibitors of cytochrome P450); synergistic substances with sedative effects and central nervous system depressants, which may increase the potential for adverse effects when used 
concomitantly, and drugs that increase the QT interval, capable of increasing the risk of life-threatening cardiac arrhythmias $(10,15,16)$.

In recent years, an increased risk of death due to overdose associated with the use of methadone has been reported in the United States $(14,17,18)$. This alarming increase is mainly associated with the use of methadone in the context of chronic pain $(14,17)$ : one in three deaths associated with prolonged use of opioids is related to methadone (12). Regarding the management of addictions, there is a statistically nonsignificant tendency towards an improvement in mortality, possibly explained by the decrease in the risk of using other illicit substances or unprescribed opioids (14). Some studies do not show changes in the risk of death when comparing methadone with other opioids, especially in scenarios where its use is strictly regulated and monitored. This suggests that mortality is associated more with inappropriate use than with the drug itself $(10,14)$.

Colombian algologists come from different clinical contexts prior to their training as pain specialists; some have informal training, others have been trained in widely varying postgraduate programs depending on form of learning, type of clinical context, duration of the training, etc.

The different scenarios of clinical practice that pain specialists face (Table 1) could facilitate or hinder the appropriate use of methadone: the limited time to perform a clinical, socialfamily and psychological approach as a first step to identify candidates to long-term opioid management; the opportunity to use tools to establish the risk of different adverse effects during treatment; the use of opioid contracts and rapid urine tests; the opportunity to educate patients about the objectives of treatment and the proper use of opioids $(9,19,20,21)$.
Table 1

Sources of variability in clinical practice of pain specialists

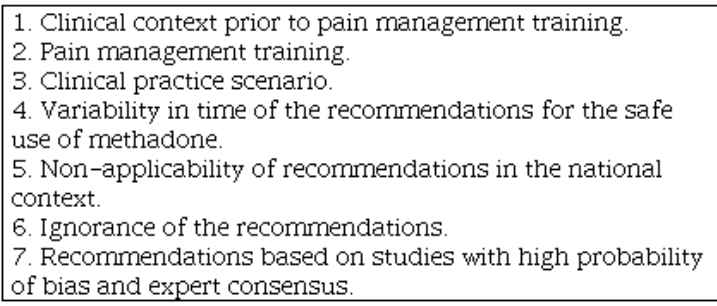

This is an observational cross-sectional study whose objectives are: (1) to know the methadone prescription patterns of Colombian pain specialists and compare them with the recommendations most accepted by the international scientific community, and (2) to find opportunities to improve these prescription, surveillance and methadone use patterns in Colombia.

\section{Materials and Methods}

After obtaining approval based on ethical, scientific and methodological criteria by the Postgraduate Division of the El Bosque University, the prescribing patterns of methadone and opioids in chronic pain management were characterized.

To this end, the databases of pain specialists in Colombia were consulted through the organizations that group them: The Colombian Association for the Study of Pain (ACED by its Spanish acronym), the Colombian Association of Palliative Care (ACCP by its Spanish acronym) and training programs for pain specialists.

Inclusion criteria: Physician, member of the group of professionals described, dedication of at least $20 \%$ of his/her professional practice to the management of chronic pain, having a personal or group email account and interest in participating in the survey.

Exclusion criteria: Other professionals responsible for the care of chronic pain patients (indirectly related to the prescription and followup of patients, but not responsible for the 
prescription), and physicians who do not perform their practice in Colombia.

It was assumed that the majority of the respondents routinely use one or several email accounts, and that the associations have updated information on their members. The respondents were asked to only send a completed form, even if they received the same information through different email accounts or at different times in the same email account $(22,23,24,25,26,27)$.

Participation was voluntary and the data provided was handled anonymously and confidentially, with no objective other than the present study.

The measurement instrument is a structured survey with four domains: (a) characterization of the surveyed population (4 questions), (b) clinical practice of the respondent (3 questions), (c) prolonged use of opioids in chronic pain patients ( 2 questions of perception, 5 questions of clinical practice, total 7 questions), and (d) use of methadone in chronic pain patients $(5$ questions of clinical practice and 1 question about knowledge of clinical practice guidelines. Total 6 questions).

A pilot test was conducted with residents of Anesthesiology who had approved their rotation on Pain Medicine, to evaluate the clarity of the language of the questions, the practicality of the questionnaire and the analysis of data. Their suggestions were analyzed and the relevant changes were made.

The variables measured are qualitative and were summarized using descriptive statistics measures; meanwhile, the associations planned in the protocol were executed with the SSPS program, version 15 . To measure the statistical significance, the Pearson chi-square test was used.

\section{Results}

After an exhaustive search of Colombian algologists through the associations and pain management training institutions in Colombia, 364 email addresses were obtained: 278 of the ACED, 53 of ACCP, 27 of the First Meeting of
Specialists in Pain Management and Palliative Care Training of academic programs of the country, organized by the ACCP on November 28, 2014, and 6 of graduates from the El Bosque University program.

There were 22 duplicate emails, 7 emails from doctors who do not reside in Colombia, and 54 from people who work with professions related to health care, but who are not physicians authorized to prescribe medications, which were eliminated. Finally, 282 addresses were considered.

In order to carry out the process, the strategies recommended by the Cochrane meta-analysis on methods to increase the response rate to online questionnaires were implemented $(28,29)$. In this way, 46 responses were obtained, representing $16 \%$ of the surveys sent.

\section{Characterization of the surveyed population}

$61 \%$ of the doctors who responded to the survey have worked in chronic pain control for more than 5 years; however, none of the categories that characterize the length of experience in the specialty represents the majority of respondents. Many respondents reported the specialty of anesthesia as a training context prior to their training in chronic pain management; $83 \%$ of the respondents indicated having a certified university education in chronic pain management (Figure 1), and 57\% reported that they received their training through a medicalsurgical specialization.

\section{Figure 1}

Training in chronic pain management

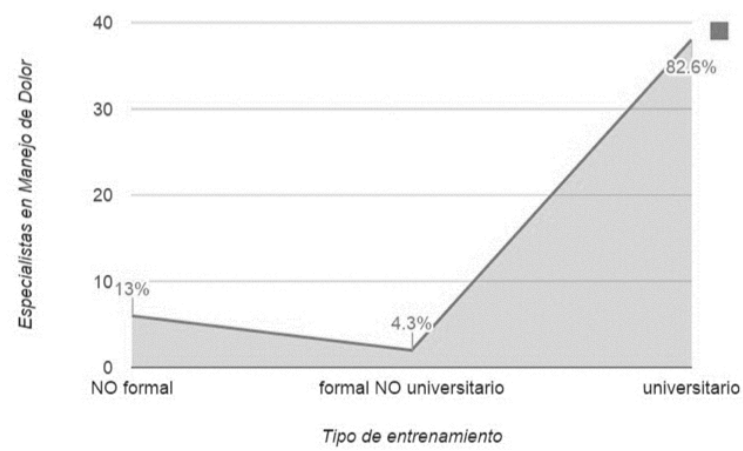


Only $4 \%$ of respondents care exclusively for oncological or non-oncological patients ( $2 \%$ and $2 \%$, respectively). The majority of respondents care both for oncological and nononcological patients. $89 \%$ of respondents see patients belonging to all categories of health insurance. $59 \%$ of respondents perform their clinical practice in a university hospital.

\section{Opioid prescription patterns in chronic pain}

The majority of respondents consider that prolonged opioid management has at least a moderate effect on pain control (Figure 2) and an improvement in the functionality of their patients. A high proportion of respondents never or almost never use validated tools to predict the possibility of opioid use disorders prior to the start of treatment (Figure 3) or rapid urine tests for patient follow-up.

\section{Figure 2}

Pain relief

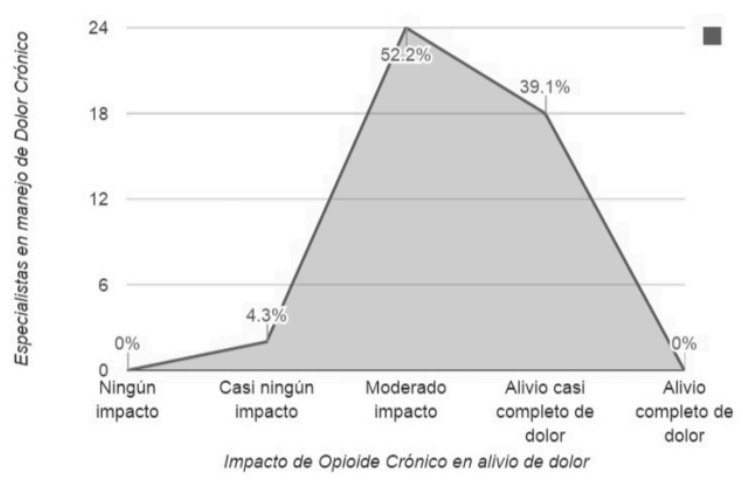

\section{Figure 3}

Use of questionnaires for the prevention of opioid use disorders

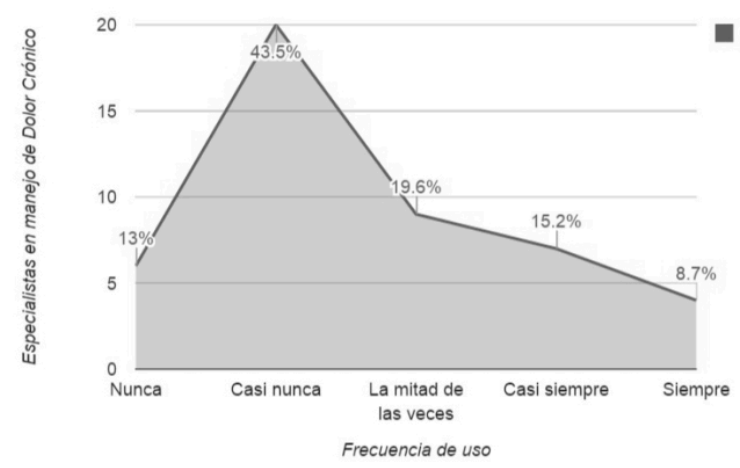

The majority of respondents explain to their patients the objectives of opioid use and establish realistic expectations about the treatment; in addition to clarifying how medication is handled at home to avoid consumption by people other than the patient.

\section{Patterns of methadone prescription}

A good portion of the professionals surveyed use a 12-lead electrocardiogram with QT interval measurement before the start and as a followup to methadone treatment. During the titration, $50 \%$ of the respondents adjust the methadone dose at intervals longer than 5 days, and 54\% consider that when rotating from another opioid to methadone the dose ratio depends on the previous exposure according to the daily amount of opioid consumed.

Most respondents consider the incomplete cross-tolerance phenomenon at the time of rotating the prescribed opioids; but in the case of methadone, there is no single quantitative form that makes it applicable uniformly in the clinical practice of the respondents. Likewise, most of them consider times longer than one week of suspension to assume the patient not exposed to opioids.

$83 \%$ of respondents know clinical practice guidelines that provide recommendations on long-term use of methadone. 
Respondents who treat oncological patients mainly or exclusively always or almost always explain to their patients how to handle opioids at home, including the inappropriateness of sharing them with other people, and the strategies to prevent theft of the drug $(\mathrm{p}=0.007)$. Respondents who never or almost never explain this to their patients have less than 3 years of experience managing chronic pain patients $(\mathrm{p}=0.004)$.

The few respondents who answered that prolonged opioid management has almost no influence on pain control, mainly see nononcological population. All respondents who mainly or exclusively see oncological patients have the impression that opioid management provides at least a moderate effect on pain control $(\mathrm{p}=0.00)$.

Half of the respondents who exclusively or mainly care for non-oncological patients perceive almost no improvement in the functionality of the patients in the long-term opioid treatment. Only one respondent who cares mainly for oncological patients thinks in the same way $(\mathrm{p}=0.034)$.

All the respondents who consider their patients not exposed to opioids after suspending methadone for one week had university training $(p=0.001) .90 \%$ of the respondents who received university training know clinical practice guidelines for prolonged methadone management compared with only 50\% of the respondents without university training $(\mathrm{p}=0.028)$.

$88 \%$ of respondents with chronic pain management training through a clinical specialization always or almost always request a 12-lead electrocardiogram with measurement of the QT interval before the start of chronic methadone treatment, compared with only $50 \%$ of the respondents who had a non-clinical training (free courses, diplomas, virtual courses and master's degrees without clinical practice) $(\mathrm{p}=0.023)$.

\section{Discussion}

This survey of Colombian physicians specialized in pain management is an initial effort to characterize opioid prescribing patterns, in general, and of methadone, particularly in a prolonged manner, in a chronic pain population, regardless of their oncological or non-oncological origin. The obtaining of email addresses was done in a profound way, including the scientific societies and pain specialist training groups in the country. Doctors not affiliated to these societies or who have not been identified through the training groups and who care for patients suffering chronic pain in Colombia are not represented by the survey, which limits the present study. No inactive email accounts were identified; however, this does not guarantee their active use.

Electronic questionnaires are an efficient way to collect information for survey-like crosssectional studies that capture trends (30)in this case, long-acting opioid prescription patterns among Colombian pain specialistsat one point in time. Strategies that have proven to increase the response rate for this type of questionnaire were used: (a) shortened electronic questionnaire, (b) interesting topic for the population under study, (c) possibility of seeing partial results at the end of the survey, (d) white background, (e) simple header, (f) no use of the word survey in the header, $(\mathrm{g})$ inclusion of a photo, and (h) no male signature.

Other strategies for increasing the response rate were not used: (a) non-monetary incentives, and (b) personalized questionnaire. These strategies were taken from the most recent Cochrane meta-analysis, which evaluates methods to increase the response rate to postal and electronic questionnaires (29). In addition, the questionnaire was sent on 3 occasions, each one separated by more than a week.

The response rate is similar to other cross-sectional studies in which electronic questionnaires were used $(23,24,31,32)$ and the low response rate becomes a general limitation for all electronic questionnaires, and not a particular point of this study. However, 
despite obtaining interesting associations from the clinical point of view and with statistical significance, these should be interpreted with care, because the doctors who take the time to answer this type of questionnaire may not adequately represent all the doctors who received the questionnaire-another limitation of this type of design. Unfortunately, non-responders could not be broadly characterized to detect differences, comparing them with responders.

The majority of respondents are anesthesiologists with more than five years of experience in the management of chronic pain patients, with university training through a medical-surgical specialization that includes clinical practice during their training in algology, working in university hospitals and who have knowledge of clinical practice guidelines for the prolonged use of methadone. This can be explained in three ways: (a) most pain doctors in Colombia have this profile and the survey adequately represents them (unlikely, in view of the limitations identified). (b) Pain specialist associations and the databases of the training organizations preferentially represent this pain specialist profile (unlikely, although the population of non-responders could not be characterized, the majority of surveys were sent to ACED members, with multiple training contexts and who practice in several regions of the country). (c) Respondents are more likely to complete this type of survey with investigative and academic purpose than another pain specialist profile (poor external validity for a different pain specialist profile).

Although the responses obtained represent an experienced and highly educated population, it is noteworthy that the majority of respondents perceive prolonged opioid management as highly effective for functional and analgesic control outcomes, outcomes not evaluated in the long term and debatable in the medium term, depending on the population evaluated $(1,2,3,12,33,34,35)$. This is striking because only $2 \%$ of respondents work exclusively with oncological patients and only $15 \%$ work preferentially with this type of patient. It is likely that oncological patients who have a shorter survival time will not have a "prolonged" treatment with opioids, and the analgesic effects in the short and medium term far outweigh the potential adverse effects, without experiencing long-term adverse effects, specifically the opioid use disorder $(3,13,35)$. However, the small number of respondents who perceive as minimal the improvement in functionality with longterm opioid management care for patients with chronic non-oncological pain.

Most of the respondents know the clinical practice guidelines, which recommend strategies such as validated questionnaires to identify patients at risk of opioid abuse, rapid urine tests and treatment agreements. It is remarkable that a minimum percentage employs these strategies in their daily clinical practice, which would be explained by one of two circumstances: (a) the strategies described are difficult to implement, and (b) doctors know the scant evidence that supports these recommendations and decide not to implement them (3).

It is more likely that respondents who received university training know the clinical practice guidelines and that in their practice they consider a patient not exposed to opioids after a week of having stopped methadone to calculate the restart dose. Doctors with chronic pain training are also more likely to request an electrocardiogram at the beginning or for treatment follow-up (36).

Regardless of the profile of the respondent, doctors do not have unified and clear guidelines when titering methadone in patients not exposed to opioids and use it in patients exposed to other opioids (rotation), which can be explained by the high pharmacokinetic variability of the drug and the variability of the established recommendations. Despite not being based on evidence with low probability of bias, there are recommendations from experts that should be adopted to achieve a more uniform and predictable clinical practice (36).

In Colombia we do not have statistics that document the problem described in developed countries; but we can extrapolate circumstances such as the uncertain effectiveness of opioids for pain control, the improvement of long- 
term functionality and the increasing impact of complications associated with chronic opioid management, such as hormonal disorders, depression, opioid use disorders or death due to overdose $(20,29,30)$. The influence of the pharmaceutical industry on education and daily clinical practice is unquestionable, and Colombia is no exception. However, the effort to educate and adequately inform the health care professionals in charge of making decisions in the process of prescribing and monitoring opioid medications can have a positive influence on us and change us from being an opiophobic country (5) to a country that prescribes opioid drugs in a rational way, avoiding the two extremes experienced by developed countries (opiophobiaindiscriminate prescription) that, inevitably, are devastating for individuals, health systems and societies.

\section{Conclusions}

Perhaps in Colombia we have problems with the availability of opioids in general $(5,6)$, and being a country where social inequality is frequent, not only misinformation and widespread opiophobia, coupled with the lack of training tools for health providers who are also uninformed, explain the two most likely dangerous extremes (6): First, inadequate availability, prescription and monitoring of opioids in clinical settings where they are effective and safe (5). Second, prescription of opioids for diseases for which they have not proven to be effective, and they put the population before a huge public health problem, which has been documented in other countries.

We must work to educate opioid prescribers for the management of chronic pain.

\section{Conflicts of interests}

There are no conflicts of interests.

\section{Funding}

The tools used for its development are mainly electronic and of free use. The use of printed or related material during the development of the project is assumed by the principal investigator.

\section{Acknowledgements}

To the Colombian Association of Palliative Care and the Colombian Association for the Study of Pain.

\section{References}

1. Campbell G, Nielsen S, Bruno R, Lintzeris N, Cohen M, Hall W, et al. The pain and opioids in treatment study: characteristics of a cohort using opioids to manage chronic non-cancer pain. Pain. 2015;156(2):231-41.

2. Lynch ME, Watson CP. The pharmacotherapy of chronic pain: A review. Pain Res Manag. 2006;11(1):11-38.

3. Deyo RA, Von Korff M, Duhrkoop D. Opioids for low back pain. BMJ. 2015 jan 5;350:g6380.

4. Kobus Am, Smith DH, Morasco BJ, Jonhson ES, Yang X, Petrik AF, Deyo RA. Correlates of higher dose opioid medication use for low back pain in primary care. J Pain. 2012;13(11):1131-8.

5. Moyano J, Figueras A. A review of opioid prescription in a teaching hospital in Colombia. J Pain Res. 2012;5:237-42.

6. Moyano JR, Figueras A. The medical consumption of opioids in Colombia, 1997-2007. J Pain Palliat Care Pharmacother. 2010;24(4):367-73.

7. Kahan M, Srivastava A, Wilson

L, Gourlay D, Midmer D. Misuse of and dependence on opioids: study 
of chronic pain patients. Can Fam Physician. 2006;52 (9):1081-7.

8. Kakko J, Heilig M, Sarman I. Buprenorphine and methadone treatment of opiate dependence during pregnancy: Comparison of fetal growth and neonatal outcomes in two consecutive case series. Drug Alcohol Depend. 2008;96(1-2):69-78.

9. Dunn KM, Saunders KW, Rutter CM, Banta CJ, Merrill JO, Sullivan $\mathrm{MD}$, et al. Overdose and prescribed opioids: Associations among chronic non-cancer pain patients. Ann Intern Med. 2010;152(2):85-92.

10. Krebs EE, Becker WC, Zerzan J, Bair MJ, McCoy K, Hui S. Comparative mortality among Department of Veterans Affairs patients prescribed methadone or longacting morphine for chronic pain. Pain. 2011;152(8):1789-95.

11. Lynch ME. A review of the use of methadone for the treatment of chronic noncancer pain. Pain Res Manag. 2005;10(3):133-44.

12. Chou R, Cruciani R, Fiellin D, Compton P, Farrar JT, Haigney MC, et al. Methadone safety: A clinical practice guideline from the american pain society and college on problems of drug dependence, in collaboration with the heart rhythm society. J Pain. 2014;15(4):321-37.

13. Baxter LE, Campbell A, DeShields M, Levounis P, Martin JA, McNicholas $\mathrm{L}$, et al. Safe methadone induction and stabilization. J Addict Med. 2013;7 (6):377-86.

14. Chou R, Weimer MB, Dana T. Methadone overdose and cardiac arrhythmia potential: Findings from a review of the evidence for an American Pain Society and College on Problems of Drug Dependence clinical practice guideline. J Pain. 2014;15(4):338-65.
15. Stallvik M, Nordstrand B, Kristensen $\varnothing$, Bathen J, Skogvoll E, Spigset O. Corrected QT interval during treatment with methadone and buprenorphine-Relation to doses and serum concentrations. Drug Alcohol Depend. 2013;129(1-2):88-93.

16. Krantz MJ, Lowery CM, Martell B a, Gourevitch MN, Arnsten JH. Effects of methadone on QTinterval dispersion. Pharmacotherapy. 2005;25(11):1523-9.

17. Weimer MB, Korthuis PT, Behonick GS, Wunsch MJ. The source of methadone in overdose deaths in Western Virginia in 2004. J Addict Med. 2011;5(3):188-202.

18. Paulozzi LJ, Logan JE, Hall AJ, McKinstry E, Kaplan JA, Crosby AE. A comparison of drug overdose deaths involving methadone and other opioid analgesics in West Virginia. Addiction. 2009;104(9):1541-8.

19. Shaiova L, Berger A, Blinderman CD, Bruera E, Davis MP, Derby $\mathrm{S}$, et al. Consensus guideline on parenteral methadone use in pain and palliative care. Palliat Support Care. 2008;6(2):165-76.

20. Warner E. Opioids for the treatment of chronic noncancer pain. Am J Med. 2012;125(12):1155-61.

21. Fine PG, Mahajan G, McPherson ML. Long-acting opioids and shortacting opioids: Appropriate use in chronic pain management. Pain Med. 2009;10(S2):S79-88.

22. van der Wees PJ, Zagers CA, de Die SE, Hendriks EJ, Nijhuisvan der Sanden NW, de Bie RA. Developing a questionnaire to identify perceived barriers for implementing the Dutch physical therapy COPD clinical practice guideline. BMC Health Serv Res. 2013;13:159. 
23. Sheehan SR, Wedisinghe L, Macleod M, Murphy DJ. Implementation of guidelines on oxytocin use at caesarean section: a survey of practice in Great Britain and Ireland. Eur J Obstet Gynecol Reprod Biol. 2010;148(2):121-4.

24. Lovell $M$, Agar $M$, Luckett $T$, Davidson PM, Green A, Clayton J. Australian Survey of Current Practice and Guideline Use in Adult Cancer Pain Assessment and Management: Perspectives of palliative care physicians. J Palliat Med. 2013;16(11):1403-9.

25. Handler J, Lackland DT. Translation of hypertension treatment guidelines into practice: a review of implementation. J Am Soc Hypertens. 2011;5(4):197-207.

26. Beehler GP, Funderburk JS, Possemato K, Vair CL. Developing a measure of provider adherence to improve the implementation of behavioral health services in primary care: a Delphi study. Implement Sci. 2013;8(1):19.

27. Von Elm E, Altman DG, Egger M, Pocock SJ, Gøtzsche PC, Vandenbroucke JP. The Strengthening the Reporting of Observational Studies in Epidemiology (STROBE) statement: Guidelines for reporting observational studies. J Clin Epidemiol. 2008;61(4):344-9.

28. Bardiau FM, Taviaux NF, Albert A, Boogaerts JG, Stadler M. An intervention study to enhance postoperative pain management. Anesth Analg. 2003;96(1):179-85, table of contents.

29. Edwards PJ, Roberts I, Clarke MJ, DiGuiseppi C, Wentz R, Kwan I, et al. Methods to increase response to postal and electronic questionnaires. Cochrane Database Syst Rev. 2009; (3):2009-11.
30. Boynton PM, Greenhalgh T. Selecting, designing, and developing your questionnaire. $\mathrm{Br}$ Med J. 2004;328(7451):1312-5.

31. Schroeck H, Healy DW, Tait AR. Airway laser procedures in children and the American Society of Anesthesiologists' Practice Advisory: A survey among pediatric anesthesiologists. Int J Pediatr Otorhinolaryngol. 2014;78(12):2140-4.

32. Nurok M, Green DST, Chisholm MF, Fins JJ, Liguori GA. Anesthesiologists' familiarity with the ASA and ACS guidelines on Advance Directives in the perioperative setting. $\mathrm{J}$ Clin Anesth. Elsevier Inc.; 2014;26(3):174-6.

33. Sehgal N, Manchikanti L, Smith HS. Prescription opioid abuse in chronic pain: A review of opioid abuse predictors and strategies to curb opioid abuse. Pain Physician. 2012;15(3 Suppl):ES67-92.

34. Ivanova JI, Birnbaum HG, Schiller M, Kantor E, Johnstone BM, Swindle RW. Real-world practice patterns, health-care utilization, and costs in patients with low back pain: The long road to guideline-concordant care. Spine J. 2011;11(7):622-32.

35. Valenstein M, Bair MJ, Ganoczy D, Mccarthy JF, Ilgen MA, Blow FC. Association Between Opioid Prescribing Patterns and Opioid Overdose-Related Deaths. JAMA. 2011;305(13):1315-21.

36. American Society of Anesthesiologists Task Force on Acute Pain Management. Practice Guidelines for Acute Pain Management in the Perioperative Setting: An Updated Report by the American Society of Anesthesiologists Task Force on Acute Pain Management. Anesthesiology. 2012;116(2):248-73. 